\title{
Lignocellulosic bioethanol production with revalorization of low-cost agroindustrial by-products as nutritional supplements
}

\author{
Maikon Kelbert ${ }^{\mathrm{a}}$, Aloia Romaní ${ }^{\mathrm{b}}$, Eduardo Coelho ${ }^{\mathrm{b}}$, Francisco B. Pereira ${ }^{\mathrm{b}}$, \\ José A. Teixeira ${ }^{\mathrm{b}}$, Lucília Domingues ${ }^{\mathrm{b}, *}$ \\ a Chemical Engineering Department, University of Joinville Region, Campus Universitário, N. 10 Paulo Malschitzki Street, 89219-710, Joinville, SC, Brazil \\ ${ }^{\mathrm{b}}$ CEB-Centre of Biological Engineering, University of Minho, Campus de Gualtar, 4710-057 Braga, Portugal
}

\section{A R T I C L E I N F O}

\section{Article history:}

Received 29 May 2014

Received in revised form 24 October 2014

Accepted 27 October 2014

\section{Keywords:}

Ethanol

Fermentation

Nutrients supplementation

Agro-industrial by-products

Lignocellulosic materials

Inhibitors

\begin{abstract}
A B S T R A C T
During the pretreatment of lignocellulosic biomass for second generation bioethanol production, fermentation inhibitors are released. To overcome this, the use of a robust industrial strain together with agro-industrial by-products as nutritional supplementation was proposed to increase ethanol productivity and yields. Two factorial experimental designs were carried out to optimize fermentation of hydrolysate from autohydrolysis of Eucalyptus globulus. The most influential variables on ethanol production were cheese whey and $\mathrm{K}_{2} \mathrm{O}_{5} \mathrm{~S}_{2}$ (potassium metabisulfite) supplementation. Nutrient addition effect was demonstrated using the whole slurry from autohydrolysis in two process configurations (separate hydrolysis and fermentation, SHF and simultaneous saccharification and fermentation, SSF). Comparing the supplemented SHF and SSF assays with non-supplemented, 2.3 and 7.4 fold higher ethanol concentrations were obtained, respectively. In the case of SSF, $50.4 \mathrm{~g} \mathrm{~L}^{-1}$ of ethanol concentration and $92.2 \%$ of ethanol conversion were attained, demonstrating an improved fermentation performance in industrial lignocellulose fermentations.
\end{abstract}

(C) 2014 Elsevier B.V. All rights reserved.

\section{Introduction}

Bioethanol from lignocellulosic materials (LCMs), also called second generation bioethanol, is considered a promising alternative to first generation bioethanol (obtained from feedstock such as sugar cane, corn, wheat or barley) (García et al., 2014). The LCMs, as Eucalyptus globulus (EGW) wood, are renewable and widespread raw materials constituting the world's largest bioethanol renewable resource. An efficient bioethanol production process from lignocellulose involves an effective pretreatment of LCM to improve the accessibility of cellulose and thus enhance the enzymatic saccharification (Buruiana et al., 2014; Singh and Bishnoi, 2013). One interesting approach is to use the whole slurry from treatment, since allows economical and industrial benefits: washing steps are avoided, water consumption is lower and the sugars from liquid phase can be used, increasing ethanol concentration (Tengborg et al., 2001). However, during the pretreatment step some compounds (such as furans, phenolic compounds and weak acids) are produced. Furfural, hydroxymethylfurfural and phenolic compounds result from degradation of pentoses, hexoses and

\footnotetext{
* Corresponding author. Tel.: +351253604402.

E-mail address: luciliad@deb.uminho.pt (L. Domingues).
}

lignin, respectively and the acetic acid is released in the deacetylation of hemicelluloses (Klasson et al., 2013). These compounds have an inhibitory effect on the microorganisms used for hydrolysate fermentation (reviewed by Palmqvist and Hahn-Hägerdal, 2000a).

In this sense, the success of lignocellulosic biomass fermentations is necessarily dependent on the ability of the yeast strains to cope with the different stresses imposed during these processes. In biomass-based fermentations, yeast cells, besides having to tolerate the presence of the above-referred inhibitors, are also exposed to nutrient starvation and the absence of oxygen (Pereira et al., 2011a). To overcome the problem of toxicity, several strategies have been considered such as a biological or chemical detoxification step prior to fermentation (reviewed by Palmqvist and Hahn-Hägerdal, 2000b) or the improvement of resistance of the organism itself (Heer and Sauer, 2008). Another possible strategy can be the optimization of fermentation environment in order to minimize the toxic effects of inhibitors (Huang et al., 2011). Supplements utilization is an alternative to facilitate the microorganism growth and fermentation in an inhibitory medium (Tomás-Pejó et al., 2012). Taking into account that the nutrient sources in the lignocellulosic hydrolysate are present in low amounts, it is important to optimize the nutritional supplementation for the improvement of fermentation performance. Several authors have reported that the use of supplements 
a)

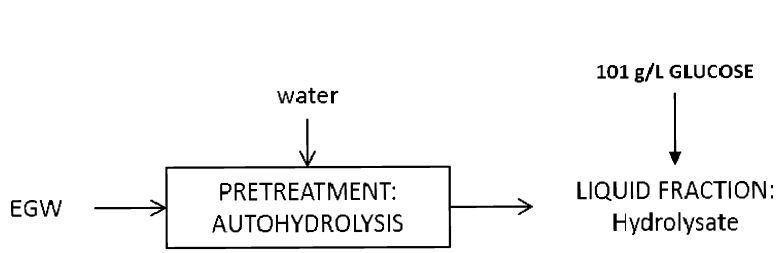

Complex Nutrients and Salts

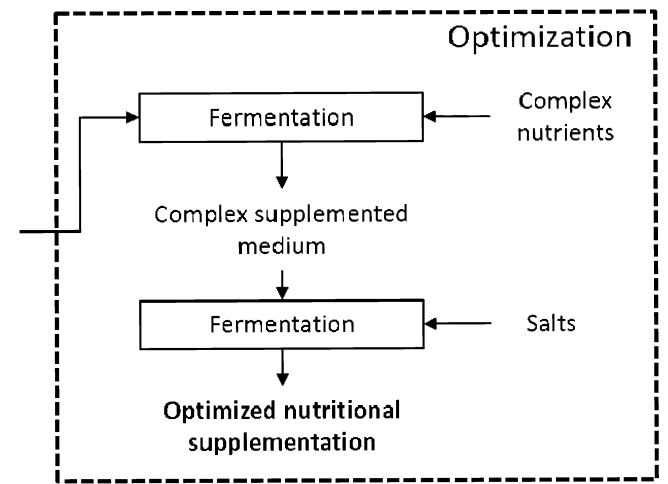

b)

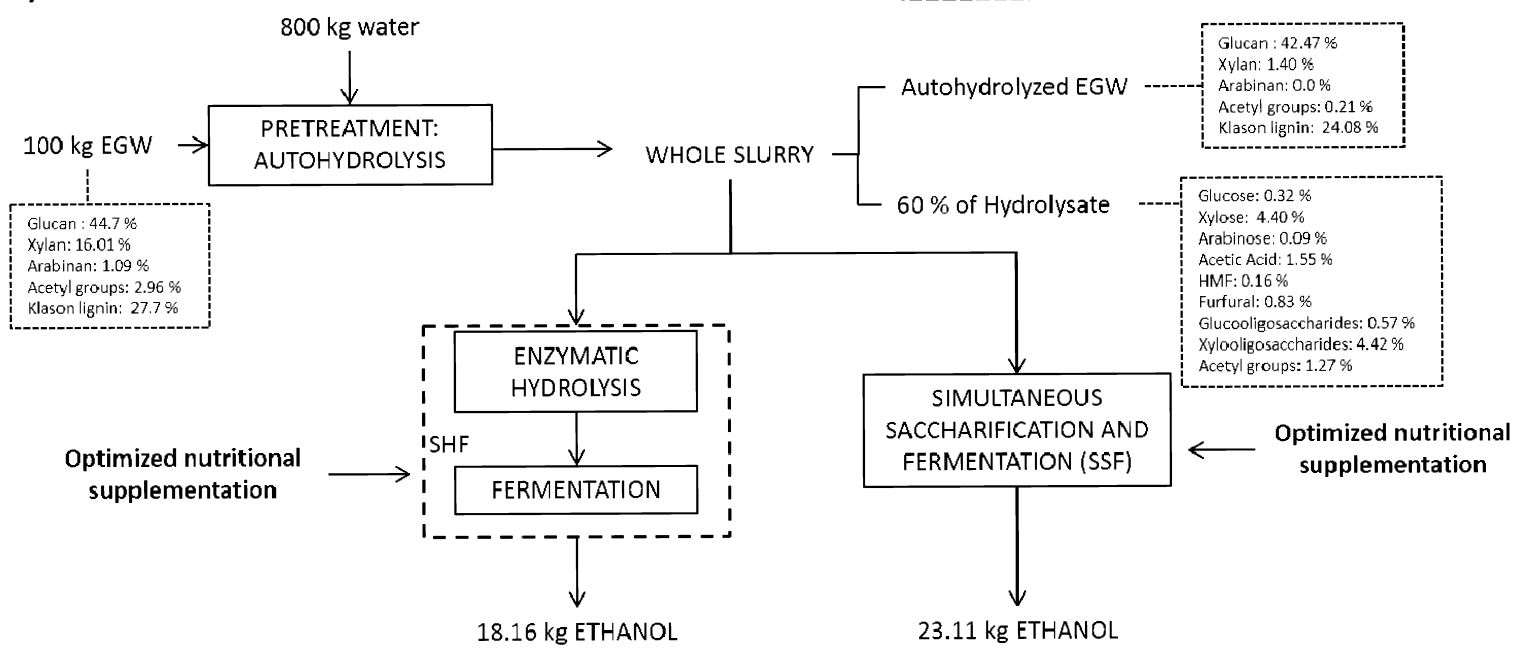

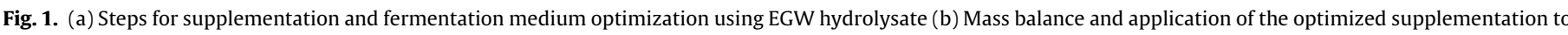
whole slurry fermentations.

is able to increase the production yield and productivity of ethanol, with or without stress conditions (Pereira et al., 2010; Jørgensen, 2009; Dragone et al., 2004). In this context, the use of residues or by-products generated in the agro-food industry is an attractive approach since it contributes to re-valorization of these residues and increases the overall economic process feasibility. Different agro-industrial residues, such as corn steep liquor (CSL), raw yeast extract (RYE), cheese whey (CW) and Urea, have been individually studied as supplements for fermentation processes supplying complex nutrients and nitrogen to the medium (Jørgensen, 2009; Salgado et al., 2009; Gullón et al., 2008). On the other hand, nutrients in minor amounts and supplied in salts, as magnesium, calcium and zinc have influence in the rate of sugar fermentation and are necessary as cofactors for several metabolic pathways (Pereira et al., 2010).

In this context, this work aims for the intensification of EGW hydrolysate fermentation processes combined with re-valorization of agro-industrial residues as low-cost nutritional supplements, in order to attain faster and higher ethanol production. For that, a previously selected industrial robust strain of Saccharomyces cerevisiae PE-2 (Pereira et al., 2014) was used for efficient fermentation. The addition of nutritional sources was evaluated, optimized and demonstrated in multiple process configurations such as separate hydrolysis and fermentation (SHF) and simultaneous saccharification and fermentation (SSF) of pretreated Eucalyptus globulus wood.

\section{Materials and methods}

\subsection{Diagram representation of experimental work}

Fig. 1 shows the structure of experimental work carried out in this study. The raw material used was obtained from autohydrolysis treatment of EGW. To study supplement effect on inhibitory medium, fermentations were performed using only hydrolysate (containing the inhibitory compounds) instead of the whole slurry. Despite the whole slurry being the most close to reality approach, the occurring of enzyme inhibition by sugars, previously analyzed in recent works (Romaní et al., 2014), could interfere with the experimental results, masking inhibitor and/or supplement effects and interfering with the models obtained in the experimental design. The hydrolysate was complemented with $101 \mathrm{~g} \mathrm{~L}^{-1}$ of glucose and employed for optimization of nutritional supplementation (complex nutrients and salts) in a two-step approach as represented in Fig. 1a. Finally, the optimized nutritional supplement was added in the saccharification and fermentation of whole-slurry fermentations (hydrolysate + autohydrolyzed EGW) for ethanol production, as represented in Fig. 1b.

\subsection{Autohydrolysis of Eucalyptus globulus wood: hydrolysate and pretreated solid}

EGW was previously analyzed by Pereira et al. (2014), containing (expressed in $\mathrm{g} / 100 \mathrm{~g}$ of raw material on dry basis, average values of three replicate \pm standard deviation): $44.7 \% \pm 0.81$ of glucan; $16.0 \% \pm 0.35$ of xylan; $1.1 \% \pm 0.05$ of arabinan; $3.0 \% \pm 0.28$ of acetyl groups; $27.7 \% \pm 0.6$ of Klason lignin and $2 \% \pm 0.2$ of extractives. EGW was submitted to autohydrolysis treatment. EGW was mixed with water at liquid-to-solid ratio (LSR) of $8 \mathrm{~kg}$ water $\mathrm{kg}^{-1}$ of oven-dry raw material in a pressurized reactor (Parr Instruments Company, Moline, IL). The autohydrolysis treatment was carried out at $150 \mathrm{rpm}$ and heated, following the heating profile (Garrote et al., 2008) up to reach the desired temperature $\left(T_{\text {MAX }}=210^{\circ} \mathrm{C}\right)$. The operational conditions were chosen on the basis of reported 
Table 1

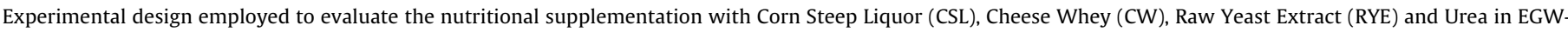
hydrolysate and results obtained (ethanol concentration at $24 \mathrm{~h}, \mathrm{E}_{24 \mathrm{~h}}$ ).

\begin{tabular}{|c|c|c|c|c|c|}
\hline \multicolumn{5}{|c|}{ Independent variables $\left(\mathrm{g} \mathrm{L}^{-1}\right)$} & \multirow{2}{*}{$\begin{array}{l}\text { Dependent variables }\left(\mathrm{g} \mathrm{L}^{-1}\right) \\
\mathrm{E}_{24 \mathrm{~h}}\left(y_{1}\right)\end{array}$} \\
\hline Run & $\operatorname{CSL}\left(x_{1}\right)$ & $\mathrm{CW}\left(x_{2}\right)$ & $\operatorname{RYE}\left(x_{3}\right)$ & Urea $\left(x_{4}\right)$ & \\
\hline 1 & 0.0 & 0.0 & 10 & 0.75 & 15.83 \\
\hline 2 & 20 & 0.0 & 10 & 0.75 & 2.420 \\
\hline 3 & 0.0 & 20 & 10 & 0.75 & 47.70 \\
\hline 4 & 20 & 20 & 10 & 0.75 & 28.91 \\
\hline 5 & 10 & 10 & 0.0 & 0.00 & 38.89 \\
\hline 6 & 10 & 10 & 20 & 0.00 & 26.93 \\
\hline 7 & 10 & 10 & 0.0 & 1.50 & 48.83 \\
\hline 8 & 10 & 10 & 20 & 1.50 & 23.58 \\
\hline 9 & 10 & 10 & 10 & 0.75 & 37.65 \\
\hline 10 & 0.0 & 10 & 10 & 0.00 & 49.66 \\
\hline 11 & 20 & 10 & 10 & 0.00 & 6.380 \\
\hline 12 & 0.0 & 10 & 10 & 1.50 & 47.89 \\
\hline 13 & 20 & 10 & 10 & 1.50 & 4.830 \\
\hline 14 & 10 & 0.0 & 0.0 & 0.75 & 34.14 \\
\hline 15 & 10 & 20 & 0.0 & 0.75 & 44.30 \\
\hline 16 & 10 & 0.0 & 20 & 0.75 & 3.640 \\
\hline 17 & 10 & 20 & 20 & 0.75 & 50.05 \\
\hline 18 & 10 & 10 & 10 & 0.75 & 34.51 \\
\hline 19 & 0.0 & 10 & 0.0 & 0.75 & 46.47 \\
\hline 20 & 20 & 10 & 0.0 & 0.75 & 50.63 \\
\hline 21 & 0.0 & 10 & 20 & 0.75 & 32.49 \\
\hline 22 & 20 & 10 & 20 & 0.75 & 4.860 \\
\hline 23 & 10 & 0. & 10 & 0.00 & 3.190 \\
\hline 24 & 10 & 20 & 10 & 0.00 & 51.08 \\
\hline 25 & 10 & 0. & 10 & 1.50 & 3.820 \\
\hline 26 & 10 & 20 & 10 & 1.50 & 51.16 \\
\hline 27 & 10 & 10 & 10 & 0.75 & 43.32 \\
\hline 28 & 10 & 10 & 10 & 0.75 & 50.40 \\
\hline 29 & 10 & 10 & 10 & 0.75 & 48.68 \\
\hline 30 & 10 & 10 & 10 & 0.75 & 47.96 \\
\hline
\end{tabular}

data (Romaní et al., 2010a). Once the intended temperature was reached, the experiment was cooled and the liquid (hydrolysate) and solid phase (autohydrolyzed EGW) were separated by filtration for analysis of chemical composition (see Section 2.8). Hydrolysate was used as media in fermentation experiments for optimization of nutritional supplementation.

\subsection{Microorganism, medium and yeast cultivation}

The strain used in this work was Saccharomyces cerevisiae PE-2, isolated from Brazilian bioethanol industry and previously shown to withstand EGW-hydrolysate inhibitory conditions (Pereira et al., 2014). Stock cultures were maintained on agar YPD plates [bacterological peptone $2 \%(\mathrm{w} / \mathrm{v})$, glucose $2 \%(\mathrm{w} / \mathrm{v})$, agar $2 \%(\mathrm{w} / \mathrm{v})$ and yeast extract $1 \%(\mathrm{w} / \mathrm{v})$ ], at $4{ }^{\circ} \mathrm{C}$. Cells were inoculated in $1 \mathrm{~L}$ Erlenmeyer flasks filled with $400 \mathrm{~mL}$ of YPD medium $\left(50 \mathrm{~g} \mathrm{~L}^{-1}\right.$ glucose, $20 \mathrm{~g} \mathrm{~L}^{-1}$ peptone and $10 \mathrm{~g} \mathrm{~L}^{-1}$ yeast extract) at $30^{\circ} \mathrm{C}$ and $150 \mathrm{rpm}$ for $24 \mathrm{~h}$. The cell suspension was aseptically collected by centrifugation for $15 \mathrm{~min}$ at $8500 \times \mathrm{g}$ and $4{ }^{\circ} \mathrm{C}$, suspended in $0.9 \%$ $\mathrm{NaCl}$ to a concentration of $200 \mathrm{mg}$ fresh yeast $\mathrm{mL}^{-1}$. The fermentation experiments were inoculated with approximately $5 \mathrm{mg}$ fresh yeast $\mathrm{mL}^{-1}$.

\subsection{Fermentations of supplemented EGW-hydrolysate}

In order to intensify ethanol production, a two-step approach as represented in Fig. 1a was performed to optimize fermentation media, using inhibitory hydrolysate medium. In a first step, the use of complex nutrients was studied, which allowed the formulation of a complex supplemented medium. In the second step, the effect of salt addition to the previously obtained medium was studied, in order to further enhance yeast performance and ethanol production.

\subsubsection{Study of complex nutrients supplementation by} Box-Behnken design

The study of complex nutritional supplementation of hydrolysate was carried out using a Box-Behnken design. The complex nutrients used in this work were: corn steep liquor (CSL), raw yeast extract (RYE), cheese whey (CW) and Urea. The experimental design contained three blocks and a central point with three replicates (30 total experiments). The ranges of variables are listed in Table 1 and were selected based on literature (Gomes et al., 2012; Li et al., 2011; Maddipati et al., 2011; Pereira et al., 2010, 2012; Silva et al., 2010; Jørgensen, 2009; Silveira et al., 2001).

The $60 \%$ of EGW-hydrolysate, diluted with water in volumetric proportion, was supplemented with $101 \mathrm{~g} \mathrm{~L}^{-1}$ of glucose and complex nutrients, according to the amounts described in Table 1. Glucose and hydrolysate were autoclaved separately $\left(121^{\circ} \mathrm{C}, 20 \mathrm{~min}\right)$ and mixed during $30 \mathrm{~min}$. The RYE was kindly provided by a microbrewery (Fermentum, Portugal), dried at $60^{\circ} \mathrm{C}$ until no weight variation, crushed and sieved. CW was kindly provided by Quinta dos Ingleses (Agro-Livestock Company, Portugal), and used directly. CW and RYE were pasteurized at $65^{\circ} \mathrm{C}$ for $30 \mathrm{~min}$ and added aseptically to the hydrolysate. CSL and urea solution were sterilized by autoclaving $\left(121^{\circ} \mathrm{C}, 20 \mathrm{~min}\right)$ and added aseptically.

Fermentation experiments were performed at $30^{\circ} \mathrm{C}$ in an orbital shaker (150 rpm) using $100 \mathrm{~mL}$ Erlenmeyer flasks (fixed volume of $30 \mathrm{~mL}$ ) fitted with perforated rubber stoppers enclosing glycerolfilled air-locks to allow exhaustion of $\mathrm{CO}_{2}$ while avoiding entrance of air. The $\mathrm{pH}$ of fermentation media was adjusted to 4.7 with $1 \mathrm{M}$ $\mathrm{NaOH}$. Fermentations were monitored by measurement of mass loss in the Erlenmeyer flasks through weighing, equivalent to $\mathrm{CO}_{2}$ production in the fermentation and directly related to fermentation rate (glucose conversion to ethanol and $\mathrm{CO}_{2}$ ) considering the process stoichiometry and the fermentation time. Glucose and ethanol concentrations were determined from samples withdrawn at $0 \mathrm{~h}$ 
Table 2

Experimental design employed to evaluate the salts addition in EGW-hydrolysate and results obtained $\left(\mathrm{CO}_{2}\right.$ exhaustion at $\left.16 \mathrm{~h}\right)$.

\begin{tabular}{|c|c|c|c|c|c|c|c|c|}
\hline \multirow[t]{2}{*}{ Run } & \multicolumn{7}{|c|}{ Independent variables $\left(\mathrm{g} \mathrm{L}^{-1}\right)$} & \multirow{2}{*}{$\begin{array}{l}\text { Dependent variable }\left(\mathrm{g} \mathrm{L}^{-1}\right) \\
\mathrm{CO}_{2} 16 \mathrm{~h}\left(\mathrm{y}_{2}\right)\end{array}$} \\
\hline & $\mathrm{MgSO}_{4}$ & $\mathrm{CuSO}_{4}$ & $\mathrm{CaCl}_{2}$ & $\mathrm{ZnCl}_{2}$ & $\mathrm{FeSO}_{4}$ & $\mathrm{KH}_{2} \mathrm{PO}_{4}$ & $\mathrm{~K}_{2} \mathrm{O}_{5} \mathrm{~S}_{2}$ & \\
\hline 1 & 0.0 & 0.00 & 0.0 & 0.01 & 0.0072 & 2 & 0.000 & 35.06 \\
\hline 2 & 5.0 & 0.00 & 0.0 & 0.0 & 0.00 & 2 & 0.334 & 42.54 \\
\hline 3 & 0.0 & 0.075 & 0.0 & 0.0 & 0.0072 & 0 & 0.334 & 12.60 \\
\hline 4 & 5.0 & 0.075 & 0.0 & 0.01 & 0.00 & 0 & 0.000 & 3.267 \\
\hline 5 & 0.0 & 0.00 & 0.8 & 0.01 & 0.00 & 0 & 0.334 & 44.52 \\
\hline 6 & 5.0 & 0.00 & 0.8 & 0.0 & 0.0072 & 0 & 0.000 & 35.33 \\
\hline 7 & 0.0 & 0.075 & 0.8 & 0.0 & 0.00 & 2 & 0.000 & 5.983 \\
\hline 8 & 5.0 & 0.075 & 0.8 & 0.01 & 0.0072 & 2 & 0.334 & 2.180 \\
\hline 9 & 2.5 & 0.038 & 0.4 & 0.005 & 0.0036 & 1 & 0.167 & 17.12 \\
\hline 10 & 0.0 & 0.00 & 0.0 & 0.01 & 0.0072 & 2 & 0.000 & 39.97 \\
\hline 11 & 5.0 & 0.00 & 0.0 & 0.0 & 0.00 & 2 & 0.334 & 44.16 \\
\hline 12 & 0.0 & 0.075 & 0.0 & 0.0 & 0.0072 & 0 & 0.334 & 10.04 \\
\hline 13 & 5.0 & 0.075 & 0.0 & 0.01 & 0.00 & 0 & 0.000 & 2.660 \\
\hline 14 & 0.0 & 0.00 & 0.8 & 0.01 & 0.00 & 0 & 0.334 & 45.43 \\
\hline 15 & 5.0 & 0.00 & 0.8 & 0.0 & 0.0072 & 0 & 0.000 & 35.83 \\
\hline 16 & 0.0 & 0.075 & 0.8 & 0.0 & 0.00 & 2 & 0.000 & 7.947 \\
\hline 17 & 5.0 & 0.075 & 0.8 & 0.01 & 0.0072 & 2 & 0.334 & 0.917 \\
\hline 18 & 2.5 & 0.038 & 0.4 & 0.005 & 0.0036 & 1 & 0.167 & 15.39 \\
\hline
\end{tabular}

and $24 \mathrm{~h}$ by HPLC. The experiments were stopped when the fastest fermenting condition of the set entered stationary phase, showing no weight variation.

\subsubsection{Study of salts supplementation by Plackett-Burman}

The effect of salts addition to the supplemented hydrolysate was evaluated using a Plackett-Burman design with central point and two replicates (total number of 18 fermentation trials). The salt concentrations were selected based on literature (Cao and Liu, 2013; Geddes et al., 2013; Hashem and Darwish, 2010; Nieves et al., 2011; Niladevi et al., 2009; Pereira et al., 2011b; Jørgensen, 2009; Silveira et al., 2001). For this, the optimized fermentation medium with complex nutrients (obtained in Section 2.4.1) was used as substrate and the addition of different salts was carried out under conditions listed in Table 2. The salts solutions (except $\mathrm{K}_{2} \mathrm{O}_{5} \mathrm{~S}_{2}$ ) were sterilized by autoclaving $\left(121^{\circ} \mathrm{C}, 20 \mathrm{~min}\right)$ and added aseptically to the medium. The $\mathrm{K}_{2} \mathrm{O}_{5} \mathrm{~S}_{2}$ was sterilized by filtration $(0.22 \mu \mathrm{m})$.

The fermentation experiments were carried as described in Section 2.4.1. The fermentation profile was measured by weight loss equivalent to $\mathrm{CO}_{2}$ production during time-course of fermentations, allowing evaluation of fermentation rates. Samples were collected and analyzed by HPLC for ethanol and glucose concentration.

\subsection{Statistical analysis}

The STATISTICA 7 software was used for generation, analysis and optimization of the experimental design, the ethanol and $\mathrm{CO}_{2}$ production were studied as response variables.

\subsection{Separate hydrolysis and fermentation (SHF) and simultaneous saccharification and fermentation (SSF) supplemented with optimized nutrients}

In order to evaluate the impact of nutritional supplementation strategy on overall process yields, two strategies of saccharification and fermentation (SHF and SSF) were conducted.

For SHF experiment, the saccharification of autohydrolyzed solid was carried out in an orbital shaker at $150 \mathrm{rpm}, 48.5^{\circ} \mathrm{C}$ and $\mathrm{pH} 4.8$, using commercial enzymes ("Cellic Ctec2" cellulases and "Cellic HTec2" hemicellulases), which were kindly provided by Novozymes (Bagsvaerd, Denmark). The cellulase activity of CTec2 was $120 \mathrm{FPU} \mathrm{mL}^{-1}$, measured as described by Ghose, (1987). $\beta$ Glucosidase and hemicellulase activity for CTec2 and HTec2 were 779.8 $\mathrm{UI} \mathrm{mL}^{-1}$ and $1690 \mathrm{UI} \mathrm{mL}^{-1}$, respectively (Paquot and Thonart,
1982; Bailey et al., 1992). In the SHF experiment, the enzyme loadings were $22.5 \mathrm{FPU} \mathrm{g}^{-1}$ and $500 \mathrm{U} \mathrm{g}^{-1}$ of cellulase and hemicellulase, respectively. The enzymatic saccharification was performed mixing the pretreated solid and hydrolysate at liquid to solid ratio (LSR) of $6.4 \mathrm{~g} \mathrm{~g}^{-1}$. The liquid was composed by $60 \%$ of hydrolysate to maintain the same conditions of experimental design. The operational conditions of enzymatic saccharification were chosen on basis of previous results (Romaní et al., 2014). The hydrolysate and pretreated solid were sterilized separately and mixed aseptically. After $96 \mathrm{~h}$ of saccharification, the medium (containing glucose from cellulose and hydrolysate) was separated from solid phase by centrifugation $(15 \mathrm{~min}$ at $8500 \times \mathrm{g})$ and used as fermentation media. The fermentation conditions were the same as described in Section 2.4 .

The SSF was carried out at $35^{\circ} \mathrm{C}$ and $\mathrm{pH}=4.8$ (using $0.05 \mathrm{~N}$ of sodium citrate buffer) in $100 \mathrm{~mL}$ Erlenmeyer flaks with orbital agitation (150 rpm). For comparative reasons, the loadings of enzymes and solids employed in SSF and SHF were the same. The SSF assay was inoculated with $8 \mathrm{mg}$ fresh yeast $\mathrm{mL}^{-1}$ of final medium. The reaction time of SSF was between 0 and $120 \mathrm{~h}$. At the desired times, samples were withdrawn from the media, centrifuged, filtered and analyzed by HPLC for ethanol and glucose concentration. The glucan conversion (GC) into glucose by enzymatic hydrolysis was calculated as determined by the National Renewable Energy Laboratory (NREL) protocols, 2004 (NREL/TP-510-42630):

$\%$ Glucan Conversion $=\frac{[\text { Glucose }]+1.053[\text { Cellobiose }]}{1.111 \times f[\text { Biomass }]} \times 100 \%$

where [Glucose] is the glucose concentration at time $t\left(\mathrm{~g} \mathrm{~L}^{-1}\right)$; [Cellobiose] is the concentration of cellobiose $\left(\mathrm{g} \mathrm{L}^{-1}\right)$ at time $t$, in the experiments cellobiose was not detected; $f$ is the glucan fraction of dry biomass ( $\mathrm{g} \mathrm{g}^{-1}$ ) [Biomass] is dry biomass or LCM concentration at the beginning of the experiment.

\subsection{Determination of fermentation parameters}

Ethanol conversion (EC, \%) was calculated as it is described the NREL protocols, 2004 (NREL/TP-510-42630):

$\%$ Ethanol Conversion $=\frac{[\text { EtOH }] f-[\text { EtOH }] 0}{0.51 \cdot f[\text { Biomass }] \times 1.111} \times 100 \%$

where [EtOH] $f$ is the ethanol concentration at the end of the fermentation $\left(\mathrm{g} \mathrm{L}^{-1}\right)$ minus any ethanol produced from the enzyme and medium; $[\mathrm{EtOH}] 0$ is the ethanol concentration at the beginning of the fermentation ( $\mathrm{g} \mathrm{L}^{-1}$ ) which should be zero; [Biomass] 
is dry biomass or LCM concentration at the beginning of the fermentation $\left(\mathrm{g} \mathrm{L}^{-1}\right)$; $f$ is the glucan fraction of dry biomass $\left(\mathrm{g} \mathrm{g}^{-1}\right)$; 0.51 is the factor for glucose to ethanol based on stoichiometric biochemistry of yeast and 1.111 is the conversion factor of glucan into equivalent glucose

The volumetric productivity $\left(Q_{p}, \mathrm{~g} \mathrm{~L}^{-1} \mathrm{~h}^{-1}\right)$ was also determined and was calculated as:

$Q_{p}=\frac{E_{t}}{t}$

where $E_{t}$ is the ethanol concentration $\left(\mathrm{g} \mathrm{L}^{-1}\right)$ at time $t, t$ is the necessary time $(\mathrm{h})$ to reach the stationary phase.

\subsection{Analytical methods}

An aliquot of hydrolysate was analyzed by HPLC for acetic acid, ethanol, furfural, glucose and hydroxymethylfurfural (HMF) determination with a Varian MetaCarb $87 \mathrm{H}$ column, eluent $\mathrm{H}_{2} \mathrm{SO}_{4}$ $0.005 \mathrm{M}$ at $60^{\circ} \mathrm{C}$ at a flow rate of $0.7 \mathrm{~mL} \mathrm{~min}^{-1}$ using a refractiveindex detector and UV detector. A second aliquot was analyzed for oligosaccharides determination by quantitative post-hydrolysis procedure (with $4 \% \mathrm{H}_{2} \mathrm{SO}_{4}$ at $121^{\circ} \mathrm{C}$ for $20 \mathrm{~min}$ ). The chemical composition of autohydrolyzed EGW was analyzed as described in Romaní et al. (2010b) for glucan, xylan and Klason lignin quantification. Total phenolic compounds of hydrolysate were determined as described in Conde et al. (2011) by absorbance measurement at $720 \mathrm{~nm}$ of the complex formed with the Folin-Ciocalteu reagent. A standard curve with caffeic acid was used for quantification of phenolic compounds, expressed as caffeic equivalents.

\section{Results and discussion}

\subsection{Autohydrolysis pretreatment: Autohydrolyzed Eucalyptus globulus wood (EGW) and hydrolysate}

The autohydrolysis treatment allows the solubilization of hemicellulose fraction of EGW and the alteration of its recalcitrant structure. The chemical composition of autohydrolyzed EGW was 59.26, 1.95 and $33.60 \%$ of glucan, xylan and Klason lignin, respectively. The glucan and Klason lignin were almost recovered quantitatively in the solid phase (95 and 86\%, respectively). On the other hand, the xylan was solubilized ( $9 \%$ of xylan remained in the pretreated solid). The composition of liquid phase after the pretreatment (hydrolysate) was $0.64 \mathrm{~g} \mathrm{~L}^{-1}$ of glucose; $8.85 \mathrm{~g} \mathrm{~L}^{-1}$ of xylose; $0.18 \mathrm{~g} \mathrm{~L}^{-1}$ of arabinose; $3.11 \mathrm{~g} \mathrm{~L}^{-1}$ of acetic acid; $0.33 \mathrm{~g} \mathrm{~L}^{-1}$ of hydroxymethylfurfural; $1.66 \mathrm{~g} \mathrm{~L}^{-1}$ of furfural; $1.15 \mathrm{~g} \mathrm{~L}^{-1}$ of glucooligosaccharides; $8.97 \mathrm{~g} \mathrm{~L}^{-1}$ of xylooligosaccharides; $2.55 \mathrm{~g} \mathrm{~L}^{-1}$ of acetyl groups and $2.01 \mathrm{~g} \mathrm{~L}^{-1}$ of phenolic compounds. The main components of hydrolysate were xylose and xylooligosaccharides that represented $60.5 \%$ of total identified compounds in the liquid phase. These results are in agreement with previously reported data (Romaní et al., 2010a,b). Taking into account the percentage of these sugars in the liquid phase, their fermentation would be of upmost interest to increase process yields, and several efforts are being made currently to obtain robust yeast strains capable of fermenting all sugars present in the hydrolysate (Demeke et al., 2013). However, as observed for glucose, xylose fermentations can only be feasible if yeasts are able to cope with the inhibitors present in the hydrolysate, which can be facilitated by proper nutritional balance of the fermentation medium.

\subsection{Study of hydrolysate fermentation supplemented with complex nutrients}

In order to provide optimal nutritional supplementation to enhance inhibitor resistance, the effect of complex nutrients (CSL,
CW, RYE and Urea) on the hydrolysate fermentation was evaluated using a Box-Behnken experimental design. The operational conditions can be seen in Table 1 .

Time course of fermentations was followed by measurement of mass losses in culture flasks, corresponding to $\mathrm{CO}_{2}$ production and exhaustion in the glycerol lock system. Mass loss data allowed the fermentation profiles construction, which showed the differences in $\mathrm{CO}_{2}$ production among the experiments during time (represented in Fig. S1, Supplementary data) related to the subsequent differences in fermentation rate. Fermentations assays finished at $24 \mathrm{~h}$, when the stationary phase was achieved in the fastest fermenting cultures. Samples were collected at the chosen time $(24 \mathrm{~h})$ for ethanol quantification (included in Table 1). The concentration of ethanol varied in the range 2.4-51.2 g. $\mathrm{L}^{-1}$ (experiments 2 and 26 , respectively).

The experimental design allowed mathematical modelling of ethanol production depending on supplement concentrations used, with a second degree polynomial regression expressed (as it is expressed in the following equation):

$y_{j}=b_{0 j}+\sum_{i=1}^{2} b_{i j} X_{i}+\sum_{i=1}^{2} \sum_{k \geq i}^{2} b_{i j k} X_{i} X_{k}$

where $y_{j}(j=1$ to 2$)$ is the dependent variable; $x_{i}$ or $x_{k}$ ( $i$ or $k$ : 1 to $3, k \geq i$ ) are the normalized, independent variables (defined in Tables 1 and 2), and $b_{0 j} \ldots b_{\mathrm{ikj}}$ are regression coefficients calculated from experimental data by multiple regression using the least-squares method.

Regression coefficients are listed in Table 3 and it can be observed that the relation between supplement concentration and ethanol production was well described by the empirical model $\left(R^{2}=0.8763\right.$ and predicted- $\left.R^{2}=0.761\right)$. The significance of regression coefficients was determined by $p$-value. Data of $p$-value $<0.10$, $<0.05$ and $<0.01$ indicate a significant level of $90 \%, 95 \%$ and $99 \%$, respectively. These results showed the influence of each factor and the interaction among factors. On basis of results observed in Table 3, the most influent variable on ethanol production was CW with $p=0.00$ (representing $>99.99 \%$ of the significance level). CSL and RYE also had a significant effect ( $>99 \%$ ) on ethanol concentration, nevertheless their addition had a negative influence on the studied variable.

For a better results interpretation, a response surface was represented (Fig. 2). Fig. 2a shows the variation of ethanol concentration at $24 \mathrm{~h}$ with independent variable CW and CSL fixed the variables Urea and RYE in 0.86 and $4.1 \mathrm{~g} \mathrm{~L}^{-1}$, respectively. The maximal concentration of ethanol $\left(54.97 \mathrm{~g} \mathrm{~L}^{-1}\right)$ was achieved for values of $\mathrm{CW}>16 \mathrm{~g} \mathrm{~L}^{-1}$ and concentration of $\mathrm{CSL}<6 \mathrm{~g} \mathrm{~L}^{-1}$. CW showed high influence on ethanol concentration in all of the experiments.

Table 3

Effects of nutrient sources on the ethanol concentration after $24 \mathrm{~h}$ of fermentation.

\begin{tabular}{lclrl}
\hline & Coefficient & Standard error & $t$-Value & $p$-Value \\
\hline$b_{0 \mathrm{j}}$ & 43.75 & 3.660 & 11.960 & 0.000 \\
$b_{1 \mathrm{j}}$ & -11.84 & 2.590 & -4.570 & 0.000 \\
$b_{11 \mathrm{j}}$ & -9.520 & 3.420 & -2.780 & 0.014 \\
$b_{2 \mathrm{j}}$ & 17.51 & 2.590 & 6.770 & 0.000 \\
$b_{22 \mathrm{j}}$ & -9.750 & 3.420 & -2.850 & 0.012 \\
$b_{3 \mathrm{j}}$ & -10.14 & 2.590 & -3.920 & 0.001 \\
$b_{33 \mathrm{j}}$ & -1.180 & 3.420 & -0.340 & 0.735 \\
$b_{4 \mathrm{j}}$ & 0.330 & 2.590 & 0.130 & 0.900 \\
$b_{44 \mathrm{j}}$ & -7.250 & 3.420 & -2.120 & 0.051 \\
$b_{12 \mathrm{j}}$ & -1.340 & 4.480 & -0.300 & 0.768 \\
$b_{13 \mathrm{j}}$ & -7.950 & 4.480 & -1.770 & 0.096 \\
$b_{14 \mathrm{j}}$ & 0.060 & 4.480 & 0.010 & 0.990 \\
$b_{23 \mathrm{j}}$ & 9.060 & 4.480 & 2.020 & 0.061 \\
$b_{24 \mathrm{j}}$ & -0.140 & 4.480 & -0.030 & 0.976 \\
$b_{34 \mathrm{j}}$ & -3.320 & 4.480 & -0.740 & 0.470 \\
\hline
\end{tabular}


a)

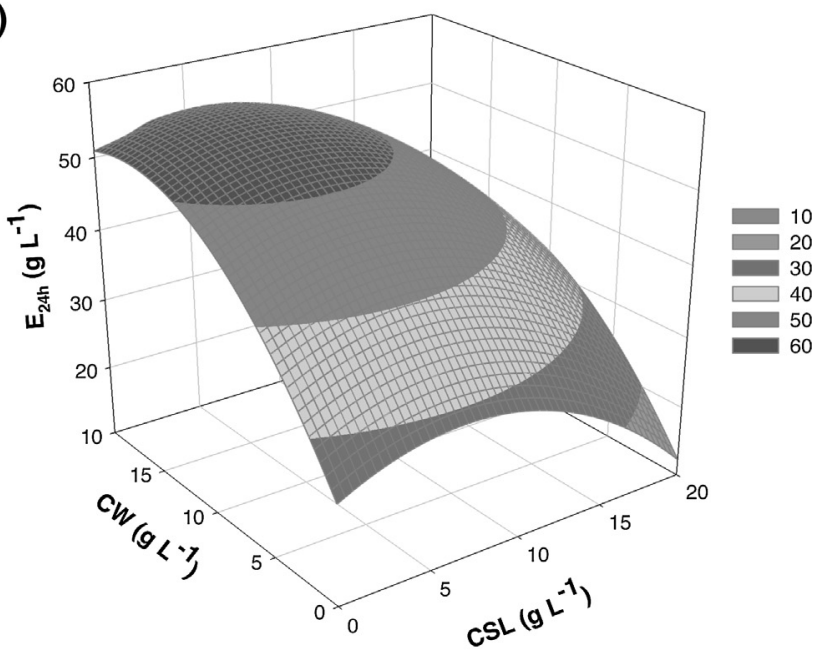

b)

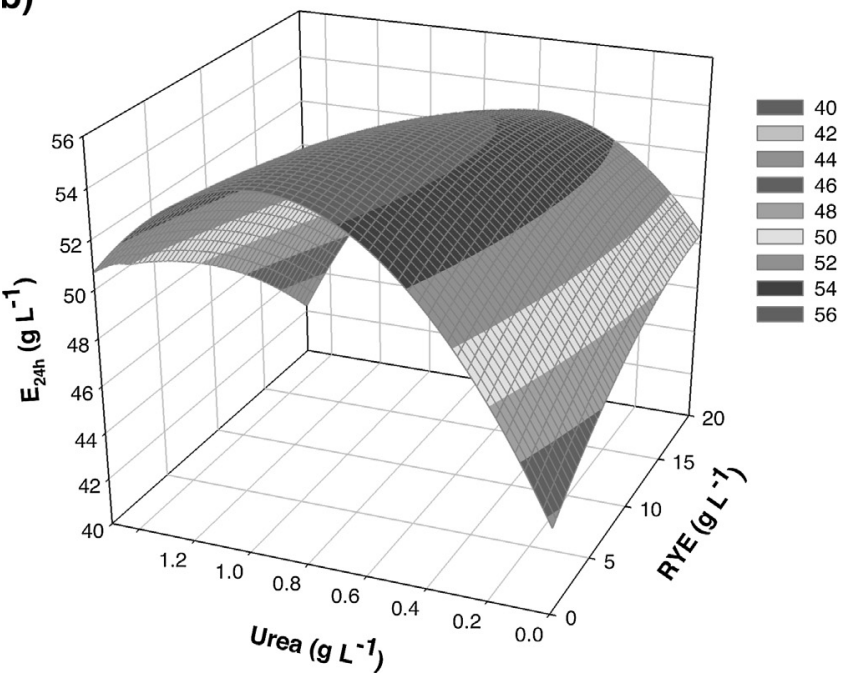

Fig. 2. Response surfaces of calculated ethanol concentration: (a) calculated dependence of ethanol concentration at $24 \mathrm{~h}\left(\mathrm{E}_{24 \mathrm{~h}}\right)$ on Cheese Whey (CW) and Corn Steep Liquor (CSL); (b) calculated dependence of ethanol concentration at $24 \mathrm{~h}\left(\mathrm{E}_{24 \mathrm{~h}}\right)$ on Urea and Raw Yeast Extract (RYE).

Ethanol concentration decreased with increasing of CSL, as can be observed in Fig. 2a. Moreover, Fig. 2b represents the effect of Urea and RYE on the ethanol production fixing the variables CW and CSL in 16.5 and $5.79 \mathrm{~g} \mathrm{~L}^{-1}$, respectively. As can be seen in Fig. $2 \mathrm{~b}$, it was not observed a significant effect of Urea on ethanol concentration at $24 \mathrm{~h}$ of fermentation. The maximal concentration of ethanol was obtained for intermediate values of Urea and RYE. This influence can be related to the supplement complex composition and a possible synergetic effect between all supplements during fermentation trial. Besides being a source of protein and nitrogen, the complex supplements used in this study also have salts, organic acids and vitamins in their constitution (Guimarães et al., 2010). Walker (2004), described the effect of metal ions in yeasts, identifying $\mathrm{K}$ and $\mathrm{Mg}$ as key minerals for growth and ethanol production, accompanied by $\mathrm{Zn}, \mathrm{Ca}, \mathrm{Cu}$, and Fe among other microelements, all of them present in the complex supplements used in this study. Furthermore, as reported by Chandrasena et al. (1997), the synergetic effect attained between these metal ions in culture media is of upmost importance for ion interaction in yeast performance

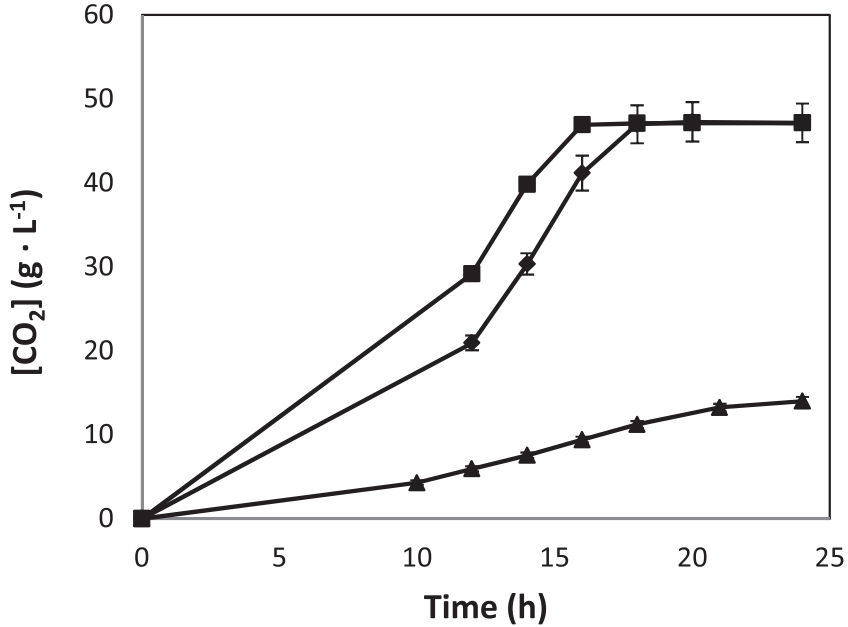

Fig. 3. Profiles of $\mathrm{CO}_{2}$ production obtained in data from the complex supplemented EGW-hydrolysate medium with $\mathrm{K}_{2} \mathrm{~S}_{5} \mathrm{O}_{2}(\boldsymbol{\nabla})$, without $\mathrm{K}_{2} \mathrm{~S}_{5} \mathrm{O}_{2}(\bullet)$ and control without any supplementation $(\boldsymbol{\Lambda})$.

reporting an optimal ion combination to maximize ethanol production, which can justify the difference in the effects and impacts observed between all supplements. Taking this into account, it can be considered that effects obtained in the model reflect a nutritional balance that goes beyond nitrogen addition, including synergies between supplements and their composition in minerals and other compounds, where CW could have the most advantageous constitution for yeast fermentation performance.

The predicted supplement concentrations for maximal ethanol production at $24 \mathrm{~h}\left(54.97 \mathrm{~g} \mathrm{~L}^{-1}\right)$ included low amount of CSL and RYE (5.79 and $4.1 \mathrm{~g} \mathrm{~L}^{-1}$, respectively), higher concentrations of CW $\left(16.5 \mathrm{~g} \mathrm{~L}^{-1}\right)$ and intermediate concentration of urea $\left(0.86 \mathrm{~g} \mathrm{~L}^{-1}\right)$. To validate the model and the values obtained, an assay using optimal concentrations was conducted. Fermentation with supplemented hydrolysate was conducted in parallel with non-supplemented hydrolysate to illustrate the experimental supplementation effect, presented in Fig. 3. As it can be seen in the results, the use of supplementation increased significantly yeast performance in comparison with the non-supplemented control. Supplemented culture was able to reach stationary phase in less than $20 \mathrm{~h}$, while non-supplemented culture was still in exponential phase. Ethanol concentration in the supplemented assay at $24 \mathrm{~h}$ was $49.06 \pm 2.31 \mathrm{~g} \mathrm{~L}^{-1}$, exceeding the value of $33.13 \mathrm{~g} \mathrm{~L}^{-1}$ obtained in the non-supplemented hydrolysate for the given time. The calculated relative error for the optimized assay was $10.67 \%$ (or $5.87 \mathrm{~g} \mathrm{~L}^{-1}$, absolute error). These data confirmed the sustainability of the model for reproducing and predicting the experimental results. A percentage of $30 \%$ more ethanol concentration was obtained in the optimized supplemented medium in comparison with the fermentation without addition of nutrients. In this sense, for the fermentation of hydrolysate with inhibitors, the composition of medium has a great effect on the fermentation performance in conformity with previous data (Tomás-Pejó et al., 2012), representing an efficient and low cost solution for industrial application.

\subsection{Evaluation of salt addition to the optimized medium with complex nutrients}

To further intensify ethanol production from the EGW hydrolysate, the effect of mineral salts addition was studied using a Plackett-Burman design, using the previously optimized supplemented medium as basis for the individual screening. Salts screening was carried out using the experimental plan described in 
Table 4

Values of significance (based on a $t$-test) of the regression coefficients and statistical parameters measuring the correlation and significance of the model developed for mineral salts screening on ethanol fermentation.

\begin{tabular}{lclcl}
\hline Term & Coefficient & Standard error & $t$-Value & $p$-Value \\
\hline$b_{0 \mathrm{j}}$ & 22.27 & $0.75-7$ & 29.42 & 0.000 \\
$b_{1 \mathrm{j}}$ & -2.166 & 0.803 & -2.697 & 0.022 \\
$b_{2 \mathrm{j}}$ & -17.33 & 0.803 & -21.58 & 0.000 \\
$b_{3 \mathrm{j}}$ & -0.760 & 0.803 & -0.946 & 0.366 \\
$b_{4 \mathrm{j}}$ & -1.277 & 0.803 & -1.590 & 0.142 \\
$b_{5 \mathrm{j}}$ & -1.536 & 0.803 & -1.913 & 0.085 \\
$b_{6 \mathrm{j}}$ & -0.682 & 0.803 & -0.849 & 0.416 \\
$b_{7 \mathrm{j}}$ & 2.271 & 0.803 & 2.828 & 0.018 \\
\hline
\end{tabular}

Section 2.4.2 under the conditions listed in Table 2. For the analysis of results, the dependent variable studied was the $\mathrm{CO}_{2}$ production at $16 \mathrm{~h}$, given that it reflects directly the variations observed in the fermentation rates (time courses of fermentation are shown in Fig. S2, Supplementary data). As described in Section 3.2, the dependent variable $\left(\mathrm{CO}_{2}\right.$ at $\left.16 \mathrm{~h}\right)$ was correlated with independent variables (mineral salts) for the evaluation of their effect on the fermentation performance using Eq. (5). An adequate adjustment of model was obtained considering that the measuring of correlation $\left(R^{2}\right)$ was 0.989 and predicted- $R^{2}$ of 0.966 . Moreover, Table 4 shows regression coefficients and statistical significance (based in the $p$-value). The coefficients of salts $\left(\mathrm{MgSO}_{4}, \mathrm{CuSO}_{4}\right.$, and $\mathrm{K}_{2} \mathrm{O}_{5} \mathrm{~S}_{2}$ ) were significant at the $95 \%$ ( $p$-values $<0.05$ ). On the other hand, $\mathrm{FeSO}_{4}$ had a significant effect $>90 \%$, the other variables $\left(\mathrm{CaCl}_{2}, \mathrm{ZnCl}_{2}\right.$ and $\left.\mathrm{KH}_{2} \mathrm{PO}_{4}\right)$ did not show a significant effect ( $p$-value $>0.1$ ) on the dependent variable. Only the presence of $\mathrm{K}_{2} \mathrm{O}_{5} \mathrm{~S}_{2}$ salt had a positive effect on $\mathrm{CO}_{2}$ production at $16 \mathrm{~h}$, as shown by the coefficients obtained in the model. The absence of positive effects and even the negative impact of most salts is coherent with the previously discussed for the complex nutrients. Salt addition effects obtained in the model suggest that further addition of salts is not necessary and even disturbs the nutritional balance optimized previously. Nevertheless, the favorable influence of $\mathrm{K}_{2} \mathrm{O}_{5} \mathrm{~S}_{2}$ can be due to the capacity to reduce or minimize the hydrolysate toxicity to the yeast cells. Geddes et al. (2013) reported that the combination of $\mathrm{pH} 9$ ammonia treatment of hydrolysate and addition of $\mathrm{K}_{2} \mathrm{O}_{5} \mathrm{~S}_{2} 1.5 \mathrm{mM}$ reduced toxicity sufficiently to allow the improvement of fermentation performance with media prepared using $100 \%$ of hydrolysate. Moreover, according to Nieves et al. (2011), the addition of $\mathrm{K}_{2} \mathrm{O}_{5} \mathrm{~S}_{2}(0.5 \mathrm{mM}$ or $1 \mathrm{mM})$ in fermentation with $30 \%$ of the hydrolysate using $E$. coli mutants, generated a substantial improvement in hydrolysate tolerance, minimizing inhibition of growth and fermentation. Additionally, these authors suggested that other toxins than furfural are being neutralized.

Considering the results obtained for $\mathrm{K}_{2} \mathrm{O}_{5} \mathrm{~S}_{2}$ in the experimental design, a validation assay was carried out adding this salt to the optimized medium with complex nutrients. Simultaneously, a non-supplemented fermentation was carried out for comparative reasons. Time course of fermentations is shown in Fig. 3 in which the effect of salt addition can be seen. The addition of $\mathrm{K}_{2} \mathrm{O}_{5} \mathrm{~S}_{2}$ to the previously optimized supplemented medium allowed further improvement of the process, leading to a significant decrease on fermentation time (of about $5 \mathrm{~h}$ ) for the same ethanol production obtained with only complex nutrients, having a subsequent impact on process productivity. Overall, the results obtained demonstrate that the use of low cost complex nutrients along with $\mathrm{K}_{2} \mathrm{O}_{5} \mathrm{~S}_{2}$ addition improved significantly the fermentation performance of PE-2 strain in the fermentation of EGW hydrolysate under high stress conditions. Ethanol concentration and productivity were improved and process efficiency was pushed towards industrial feasibility.

\subsection{Application of optimized complex and salt nutrients on SHF and SSF configurations}

For a more close-to-reality approach, the autohydrolyzed EGW was used as source of glucose by the saccharification of cellulose present in pretreated EGW. In order to evaluate the efficiency of the optimized nutritional supplementation (containing CSL, CW, RYE, Urea and $\mathrm{K}_{2} \mathrm{O}_{5} \mathrm{~S}_{2}$ ), in configurations suitable for industrial application, its nutritional effect was tested on two second generation ethanol productions using distinct process configurations. The strategies employed were: separate hydrolysis and fermentation (SHF) and simultaneous saccharification and fermentation (SSF). The saccharification and fermentation experiments were carried out under conditions mentioned in Section 2.6, in which enzymatic hydrolysis was evaluated for saccharification of whole slurry from autohydrolyzed EGW and the results obtained of glucose concentration saccharification yield were satisfactory. Additionally, a fermentation assay without supplementation was carried out for comparison and validation of supplementation effect.

\subsubsection{Separate hydrolysis and fermentation (SHF)}

The autohydrolyzed EGW was mixed with $60 \%$ of hydrolysate. This slurry (hydrolysate + solid) was saccharified by enzymes obtaining a fermentable medium composed by $88.42 \mathrm{~g} \mathrm{~L}^{-1}$ of glucose, $18.60 \mathrm{~g} \mathrm{~L}^{-1}$ of xylose, $2.6 \mathrm{~g} \mathrm{~L}^{-1}$ of acetic acid, $0.2 \mathrm{~g} \mathrm{~L}^{-1}$ of $\mathrm{HMF}$ and $0.57 \mathrm{~g} \mathrm{~L}^{-1}$ of furfural after $96 \mathrm{~h}$ of saccharification. These results show a high yield of saccharification $(G C=94.4 \%)$ with an elevated concentration of glucose. Fig. 4a shows the results obtained during SHF experiments. As it can be observed, the $\mathrm{CO}_{2}$ production was much faster in supplemented medium, reaching the stationary phase within $14 \mathrm{~h}$ of fermentation corresponding to a high volumetric productivity $\left(Q_{p}\right)$ of $2.7 \mathrm{~g} \mathrm{~L}^{-1} \mathrm{~h}^{-1}$. The experiment without nutrient supplementation achieved the stationary phase at $27 \mathrm{~h}$ (see Fig. $4 \mathrm{a}$ ) with a $Q_{p}$ of $1.58 \mathrm{~g} \mathrm{~L}^{-1} \mathrm{~h}^{-1}$. As it can be seen in Fig. 4a, the fermentation with nutrient supplementation showed an improvement on fermentation rate, as observed for $\mathrm{CO}_{2}$ production at $14 \mathrm{~h}$ being 2.3 fold more when compared with the nonsupplemented fermentation. The ethanol production after $14 \mathrm{~h}$ was calculated in basis of $\mathrm{CO}_{2}$ concentration in the experiments. In the supplemented experiment with complex and salt nutrients, $39.6 \mathrm{~g} \mathrm{~L}^{-1}$ of ethanol was obtained while in the non-supplemented assays $17.1 \mathrm{~g} \mathrm{~L}^{-1}$ of ethanol was achieved. Thus, the utilization of the optimized supplement in the SHF assay leads to a more efficient fermentative performance. The supplemented assay obtained a higher Ethanol Conversion (EC) than the non-supplemented experiment, of 88 and 38\%, respectively. Similar concentration of ethanol was obtained from steam exploded corn stover supplemented with CSL ( $\left.40 \mathrm{~mL} \mathrm{~L}^{-1}\right)$ using an engineered strain for resistance, nevertheless 1.45 lower productivity was achieved (Li et al., 2011).

\subsubsection{Simultaneous saccharification and fermentation (SSF)}

The fermentative production of ethanol from LCM can be carried out in a single step (SSF) which presents more advantages than SHF such as: (i) decreased product inhibition, (ii) limited operational costs and (iii) decreased contamination risks (Sassner et al., 2008). Fig. 4b shows ethanol and glucose concentrations of SSF experiments (with and without complex nutrients). In the nonsupplemented experiment $65.6 \mathrm{~g} \mathrm{~L}^{-1}$ of glucose and $6.8 \mathrm{~g} \mathrm{~L}^{-1}$ of ethanol were obtained at $120 \mathrm{~h}$. These data indicate that strain was not able to ferment all glucose present in the medium without nutritional supplementation and therefore, EC was low (13.0\%). On the other hand in experiment with supplementation, the glucose was practically consumed after $6 \mathrm{~h}$, since it was not observed glucose accumulation. The ethanol obtained in the supplemented SSF assay was $50.4 \mathrm{~g} \mathrm{~L}^{-1}$. Comparing the maximum ethanol production in both experiments, 7.41 fold more ethanol was produced in 


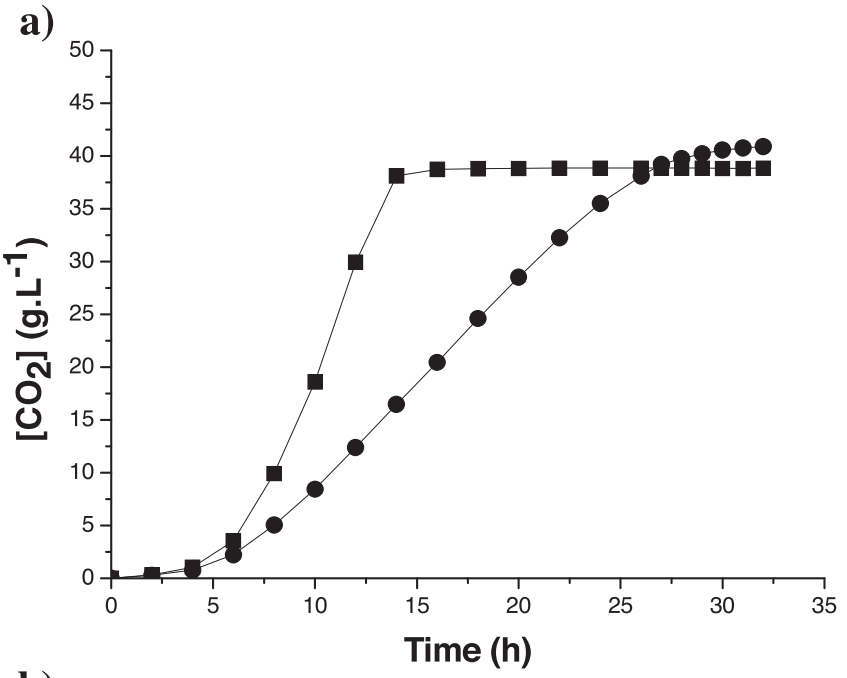

b)

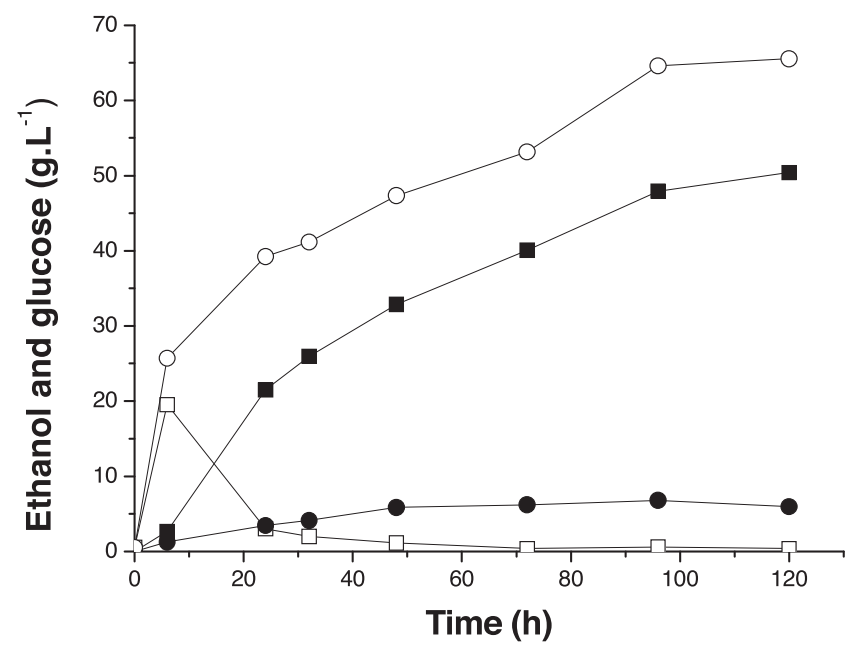

Fig. 4. (a) Profiles of $\mathrm{CO}_{2}$ production assay with ( $(\mathbf{\square})$ and without $(\bullet)$ supplementation in Separate Hydrolysis Fermentation (SHF); (b) Profiles of glucose ( $\square$ ) and ethanol $(\boldsymbol{\square})$ concentrations with supplementation and glucose $(\bigcirc)$ an ethanol $(\bullet)$ concentrations without supplementation in Simultaneous Saccharification and Fermentation (SSF).

experiment with nutrient supplementation. EC of nutritional supplemented SSF assay was $96.1 \%$ showing a good ethanol production performance. Remarkably, the supplementation strategy followed rendered the SSF process feasible with satisfactory ethanol yields and productivity. Without supplement utilization, SSF fermentation was compromised, as shown by glucose accumulation during the time course of fermentation.

Finally, comparing the results obtained in SHF and SSF, the supplemented assays showed overall higher ethanol concentration. Overall, supplement effect was highlighted for multiple process configurations demonstrating the importance of the described supplementation in the feasibility of $2^{\text {nd }}$ generation ethanol production from EGW.

\section{Conclusions}

An intensified process of 2nd generation bioethanol was attained by addition of agro-industrial by-products and salts as nutritional supplements. The optimized supplementation in SSF and SHF lead to high fermentation performances with high ethanol yields ( 96 and $88 \%$, respectively). Ethanol production in the supplemented SSF and SHF processes was 7.41 and 2.3 fold higher comparing with non-supplemented assays. Overall results demonstrate that low-cost nutritional strategy allowed the intensification (in case of SSF) and even the unblocking (in case of SHF) of second generation ethanol production from EGW-hydrolysate, representing a technology for further application to other raw-materials and fermentation processes.

\section{Acknowledgements}

The authors, A. Romaní and F.B. Pereira, thank Portuguese Foundation for Science and Technology (FCT, Portugal) for their fellowships (grant numbers, SFRH/BPD/77995/2011 and SFRH/BD/64776/2009, respectively). Research described in this article was financially supported by FEDER and "Fundação para a Ciência e a Tecnologia" (FCT): Strategic Project PEstOE/EQB/LA0023/2013, Project "Biolnd - Biotechnology and Bioengineering for improved Industrial and Agro-Food processes, REF. NORTE-07-0124-FEDER-000028" Co-funded by the Programa Operacional Regional do Norte (ON.2-O Novo Norte) QREN, FEDER.

\section{Appendix A. Supplementary data}

Supplementary data associated with this article can be found, in the online version, at http://dx.doi.org/10.1016/j.indcrop.2014. 10.056 .

\section{References}

Bailey, M.J., Biely, P., Poutanen, K., 1992. Interlaboratory testing of methods for assay of xylanase activity. J. Biotechnol. 23, 257-270.

Buruiana, C. T. Vizireanu, C. Garrote, G. Parajó, J.C. 2014 Optimization of corn stove biorefinery for coproduction of oligomers and second generation bioethanol using non-isothermal autohydrolysis. Ind. Crops Prod. 54, 32-39.

Cao, W., Liu, R., 2013. Screening and optimization of trace elements supplement in sweet sorghum juice for ethanol production. Biomass Bioenergy 50, 45-51.

Chandrasena, G., Walker, G.M., Staines, H.J., 1997. Use of response surfaces to investigate metal ion interactions in yeast fermentations. J. Am. Soc. Brew. Chem. 55, 24-29.

Conde, E., Moure, A., Domínguez, H., Parajó, J.C., 2011. Production of antioxidants by non-isothermal autohydrolysis of lignocellulosic wastes. LWT-Food Sci. Technol. 44, 436-442.

Demeke, M.M., Dumortier, F., Li, Y., Broeckx, T., Foulquié-Moreno, M.R., Thevelein, J.M., 2013. Combining inhibitor tolerance and D-xylose fermentation in industrial Saccharomyces cerevisiae for efficient lignocellulose-based bioethanol production. Biotechnol. Biofuels 6, 20.

Dragone, G., Silva, D.P., de Almeida e Silva, J.B., 2004. Factors influencing ethano production rates at high-gravity brewing. LWT-Food Sci. Technol. 37, 797-802

García, A., González-Alriols, M., Labidi, J., 2014. Evaluation of different lignocellulosic raw materials as potential alternative feedstocks in biorefinery process. Ind. Crops. Prod. 53, 102-110.

Garrote, G., Yánez, R., Alonso, J.L., Parajo, J.C., 2008. Coproduction of oligosaccharides and glucose from corncobs by hydrothermal processing and enzymatic hydrolysis. Ind. Eng. Chem. Res. 47, 1336-1345.

Geddes, C.C., Mullinnix, M.T., Nieves, I.U., Hoffman, R.W., Sagues, W.J., York, S.W. Shanmugam, K.T., Erickson, J.E., Vermerris, W.E., Ingram, L.O., 2013. Seed train development for the fermentation of bagasse from sweet sorghum and sugarcane using a simplified fermentation process. Bioresour. Technol. 128, 716-724.

Ghose, T.K., 1987. Measurement of cellulase activities. Pure Appl. Chem. 59, 257-268.

Gomes, D.G., Guimarães, P.M.R., Pereira, F.B., Teixeira, J.a, Domingues, L., 2012 Plasmid-mediate transfer of FLO1 into industrial Saccharomyces cerevisiae PE-2 strain creates a strain useful for repeat-batch fermentations involving flocculation-sedimentation. Bioresour. Technol. 108, 162-168.

Gullón, B., Alonso, J.L., Parajó, J.C., 2008. Experimental evaluation of alternative fermentation media for L-lactic acid production from apple pomace. J. Chem. Technol. Biotechnol. 617, 609-617.

Guimarães, P.M.R., Teixiera, J.A., Domigues, L., 2010. Fermentation of lactose to bioethanol by yeast as part of integrated solutions for the valorisation of cheese whey. Biotechnol. Adv. 28, 375-384.

Hashem, M., Darwish, S.M.I., 2010. Production of bioethanol and associated byproducts from potato starch residue stream by Saccharomyces cerevisiae. Biomass Bioenergy 34, 953-959

Heer, D., Sauer, U., 2008. Identification of furfural as a key toxin in lignocellulosic hydrolysates and evolution of a tolerant yeast strain. Microb. Biotechnol. 1 (6), 497-506.

Huang, R., Su, R., Qi, W., He, Z., 2011. Bioconversion of lignocellulose into bioethanol: process intensification and mechanism research. BioEnergy Res. 4, 225-245. 
Jørgensen, H., 2009. Effect of nutrients on fermentation of pretreated wheat straw at very high dry matter content by Saccharomyces cerevisiae. Appl. Biochem. Biotechnol. 153, 44-57.

Klasson, K.T., Dien, B.S., Hector, R.E., 2013. Simultaneous detoxification, saccharification, and ethanol fermentation of weak-acid hydrolysates. Ind. Crops Prod. 49, 292-298.

Li, Y., Gao, K., Tian, S., Zhang, S., Yang, X., 2011. Evaluation of Saccharomyces cerevisiae Y5 for ethanol production from enzymatic hydrolysate of non-detoxified steamexploded corn stover. Bioresour. Technol. 102, 10548-10552.

Maddipati, P., Atiyeh, H.K., Bellmer, D.D., Huhnke, R.L., 2011. Ethanol production from syngas by Clostridium strain P11 using corn steep liquor as a nutrient replacement to yeast extract. Bioresour. Technol. 102, 6494-6501.

Nieves, I.U., Geddes, C.C., Miller, E.N., Mullinnix, M.T., Hoffman, R.W., Fu, Z., Tong, Z., Ingram, L.O., 2011. Effect of reduced sulfur compounds on the fermentation of phosphoric acid pretreated sugarcane bagasse by ethanologenic Escherichia coli. Bioresour. Technol. 102, 5145-5152.

Niladevi, K.N., Sukumaran, R.K., Jacob, N., Anisha, G.S., Prema, P., 2009. Optimization of laccase production from a novel strain-Streptomyces psammoticus using response surface methodology. Microbiol. Res. 164, 105-113.

NREL, 2004. Chemical Analysis and Testing Laboratory Analytical Procedures (CAT). 586 National Renewable Energy Laboratory, Golden, CO, USA http://587 www.nrel.gov/biomass/analytical_procedures.html

Palmqvist, E., Hahn-Hägerdal, B., 2000a. Fermentation of lignocellulosic hydrolysates. II: Inhibitors and mechanisms of inhibition. Bioresour. Technol. 74, 25-33.

Palmqvist, E., Hahn-Hägerdal, B., 2000b. Fermentation of lignocellulosic hydrolysates. I: Inhibition and detoxification. Bioresour. Technol. 74, 17-24.

Paquot, M., Thonart, P., 1982. Hydrolyse enzymatique de la cellulose régénérée. Holzforschung 36, 177-181.

Pereira, F.B., Gomes, D.G., Guimarães, P.M.R., Teixeira, J.A., Domingues, L., 2012. Cell recycling during repeated very high gravity bio-ethanol fermentations using the industrial Saccharomyces cerevisiae strain PE-2. Biotechnol. Lett. 34, 45-53.

Pereira, F.B., Guimarães, P.M., Gomes, D.G., Mira, N.P., Teixeira, M.C., Sá-Correia, I., Domingues, L., 2011a. Identification of candidate genes for yeast engineering to improve bioethanol production in very high gravity and lignocellulosic biomass industrial fermentations. Biotechnol. Biofuels 4, 57.

Pereira, F.B., Guimarães, P.M.R., Teixeira, J.A., Domingues, L., 2010. Optimization of low-cost medium for very high gravity ethanol fermentations by Saccharomyces cerevisiae using statistical experimental designs. Bioresour. Technol. 101, 7856-7863.
Pereira, F.B., Guimarães, P.M.R., Teixeira, J.A., Domingues, L., 2011b. Robust industria Saccharomyces cerevisiae strains for very high gravity bio-ethanol fermentations. J. Bosci. Bioeng. 112, 130-136.

Pereira, F.B., Romaní, A., Ruiz, H.A., Teixeira, J.A., Domingues, L., 2014. Industrial robust yeast isolates with great potential for fermentation of lignocellulosic biomass. Bioresour. Technol. 161, 192-199.

Romaní, A., Garrote, G., Alonso, J.L., Parajó, J.C., 2010a. Bioethanol production from hydrothermally pretreated Eucalyptus globulus wood. Bioresour. Technol. 101, 8706-8712.

Romaní, A., Garrote, G., Alonso, L., Parajo, J.C., 2010b. Experimental assessment on the enzymatic hydrolysis of hydrothermally pretreated Eucalyptus globulus wood. Ind. Eng. Chem. Res. 49, 4653-4663.

Romaní, A., Ruíz, H.A., Pereira, F.B., Teixeira, J.A., Domingues, L., 2014. Integrated approach for effective bioethanol production using whole slurry from autohydrolyzed Eucalyptus globulus wood at high-solid loadings. Fuel 135, 482-491.

Salgado, J.M., Rodríguez, N., Cortés, S., Domínguez, J.M., 2009. Development of cost-effective media to increase the economic potential for larger-scale bioproduction of natural food additives by Lactobacillus rhamnosus, Debaryomyces hansenii, and Aspergillus niger. J. Agric. Food Chem. 57, 10414-10428.

Sassner, P., Galbe, M., Zacchi, G., 2008. Techno-economic evaluation of bioethanol production from three different lignocellulosic materials. Biomass Bioenergy 32 $422-430$

Silva, A.C., Guimarães, P.M.R., Teixeira, J.a, Domingues, L., 2010. Fermentation of deproteinized cheese whey powder solutions to ethanol by engineered Saccharomyces cerevisiae: effect of supplementation with corn steep liquor and repeated-batch operation with biomass recycling by flocculation. J. Ind. Microbiol. Biotechnol. 37, 973-982.

Silveira, M.M., Wisbeck, E., Hoch, I., Jonas, R., 2001. Production of glucose-fructose oxidoreductase and ethanol by Zymomonas mobilis ATCC 29191 in medium containing corn steep liquor as a source of vitamins. Appl. Microbiol. Biotechnol 55 $442-445$.

Singh, A., Bishnoi, N.R., 2013. Ethanol production from pretreated wheat straw hydrolysate by Saccharomyces cerevisiae via sequential statistical optimization. Ind. Crops Prod. 41, 221-226.

Tomás-Pejó, E., Negro, M.J., Sáez, F., Ballesteros, M., 2012. Effect of nutrient addition on preinoculum growth of S. cerevisiae for application in SSF processes. Biomass Bioenergy 45, 168-174.

Tengborg, E., Galbe, M., Zacchi, G., 2001. Reduced inhibition of enzymatic hydrolisis of steam-pretreated softwod. Enzyme Microb. Technol. 28, 835-844.

Walker, G.M., 2004. Metals in yeast fermentation processes. Adv. Appl. Microbiol. 54, 197-229. 